\title{
Balanço de energia em um solo cultivado com feijão caupi no brejo paraibano ${ }^{1}$
}

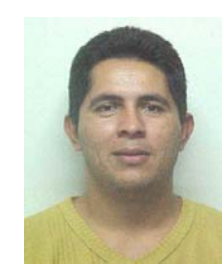

José R. de S. Lima ${ }^{2}$, Antonio C. D. Antonino ${ }^{3}$, Willames de A. Soares ${ }^{3}$, Edvane Borges ${ }^{3}$, Ivandro de F. da Silva² \& Carlos A. B. de O. Lira ${ }^{3}$

\footnotetext{
1 Parte da Tese do primeiro autor, apresentada ao PROTEN/DEN, UFPE.

2 UFPB/CCA/DSER, CEP 58397-000, Areia, PB. Fone: (83) 362-2300. E-mail: romualdosolo@yahoo.com (Foto), ivandro@cca.ufpb.br

3 UFPE/DEN, Av. Prof. Luís Freire 1000, Cidade Universitária, CEP 50740-540, Recife, PE. Fone: (81) $2126-8252$. E-mail: acda@ufpe.br; willamess@yahoo.com.br; edvborges@yahoo.com; cabol@ufpe.br
}

Protocolo $10-9 / 2 / 2004$ - Aprovado em 6/4/2005

\begin{abstract}
Resumo: Os componentes do balanço de energia num solo cultivado com feijão caupi nas condições do Brejo Paraibano, foram determinados numa área de 4 ha do Centro de Ciências Agrárias, da UFPB, localizada no município de Areia, PB (6 $58^{\circ} \mathrm{S}, 35^{\circ} 41^{\prime} \mathrm{W}$ e $\left.620 \mathrm{~m}\right)$. Para tal, instalou-se uma torre no centro da área, contendo um pluviógrafo, um piranômetro, um saldo radiômetro e sensores para medida da temperatura e da umidade relativa do ar, em dois níveis acima do dossel da cultura; além disso, dois locais no solo foram instrumentados, cada um com duas sondas térmicas instaladas horizontalmente, nas profundidades de $z=2,0 \mathrm{~cm} \mathrm{e} \mathrm{z}=8,0$ $\mathrm{cm}$, além de uma placa destinada à medida do fluxo de calor no solo, a $5,0 \mathrm{~cm}$. Essas medidas foram armazenadas a cada $30 \mathrm{~min}$, num sistema de aquisição de dados. Verificou-se que o valor médio do saldo de radiação (Rn) foi de $78 \%$, sendo a $\mathrm{Rn}$ utilizada, em média, como $71 \%$ no fluxo de calor latente (LE), $19 \%$ como fluxo de calor sensível (H) e $10 \%$ como fluxo de calor no solo (G). A fração do saldo de radiação utilizada como fluxo de calor latente aumentou com a evolução da cobertura do solo pela cultura, enquanto a fração utilizada como fluxo de calor sensível e de calor no solo, diminuiu.
\end{abstract}

Palavras-chave: razão de Bowen, saldo de radiação, fluxo de calor latente, fluxo de calor sensível, fluxo de calor no solo

\section{Energy balance in a soil cultivated with cowpeas in a mountaineous area in Paraiba, Brazil}

\begin{abstract}
The energy balance components in a cowpea crop growing in the mountain region of Paraiba, Brazil ("Brejo Paraibano") was determined in a 4 ha area in the Centro de Ciências Agrárias, UFPB, in the municipality of Areia, PB (6 $58^{\circ} \mathrm{S}, 35^{\circ} 41^{\prime} \mathrm{W}$ e $620 \mathrm{~m}$ ). Measurements of rainfall, net and global radiation were made. Sensors at two levels above the canopy were also mounted, allowing the measurements of air temperature and relative humidity. Below the soil surface, two different sites were provided with two thermal probes, horizontally installed at depths of 2.0 and $8.0 \mathrm{~cm}$, besides a heat flux plate $5.0 \mathrm{~cm}$ deep for soil heat flux measurements. All data were stored in a datalogger each $30 \mathrm{~min}$. The average value of the net radiation was $78 \%$ of the global solar radiation, in which $71 \%$ appeared as latent heat flux, $19 \%$ as sensible heat flux and $10 \%$ as soil heat flux. The fractional content of the latent heat flux in the net radiation increased as the soil covered by the crop increased, while the two other components decreased.
\end{abstract}

Key words: Bowen ratio, net radiation, latent heat flux, sensible heat flux, soil heat flux

\section{INTRODUÇÃO}

A produção e o consumo do feijão caupi (Vigna unguiculata (L). Walp), estão espalhados por vastas áreas das Américas Central e do Sul, pelas áreas do sudeste e sudoeste da América do Norte, e em áreas do oeste da África, Índia, sul e sudeste da Ásia, Austrália e sul da Europa. Na América do Sul a região mais produtora é o nordeste do Brasil (Ehlers \& Hall, 1997). 
O feijão caupi ou macassar, é o alimento básico das populações mais pobres, exercendo importante função social no suprimento das necessidades nutricionais, além de desempenhar papel fundamental na composição da produção agrícola brasileira, particularmente do Nordeste (Cordeiro et al., 1998).

Apesar da significância do feijão caupi, infelizmente poucos trabalhos relacionados ao estudo dos componentes do balanço de energia dessa cultura, foram realizados até agora (San José et al., 2003); ressalta-se que a maior parte dos trabalhos referentes aos componentes do balanço de energia em feijão, refere-se à espécie Phaseolus vulgaris (Albuquerque, 1997; Silva, 2000).

O balanço de energia das superfícies vegetadas permite dimensionar as trocas de massa e energia no sistema soloplanta-atmosfera, através do estudo da partição do saldo de radiação nos diversos processos que ocorrem na cultura. $\mathrm{O}$ método autoriza que se avaliem as alterações no microclima da vegetação, em função dos estádios de desenvolvimento da cultura e das condições de solo e atmosfera (Fontana et al., 1991).

O método do balanço de energia-razão de Bowen tem sido largamente utilizado por vários pesquisadores (Sauer et al., 1998; Perez et al., 1999; Teixeira, 2001; San José et al., 2003), porém, de acordo com Steduto \& Hsiao (1998), esta técnica deve ser usada com cautela, pois não reflete a natureza turbulenta do processo de evapotranspiração.

De acordo com Fritschen \& Simpson (1989), o método da razão de Bowen ( $\beta=\mathrm{H} / \mathrm{LE}$ ) é baseado em várias suposições, quais sejam: no transporte, assumido para ser na direção vertical, sem advecção de energia; assume-se que os sensores que medem os gradientes estão localizados dentro da camada de fluxo conservativo, onde os fluxos são constantes com a altura; na superfície, homogênea em relação às fontes e sumidouros de calor e vapor d'água; assume-se a igualdade entre os coeficientes de transferência turbulenta de calor sensível (Kh) e latente (Kw); as duas primeiras suposições são facilmente encontradas se um fetch adequado estiver disponível (Todd et al., 2000).

As principais vantagens do método da razão de Bowen, são: medições simples e diretas; não requererem informações a respeito das características aerodinâmicas da superfície de interesse; podem integrar fluxos de calor latente sobre grandes áreas (de centenas a milhares de metros quadrados); podem estimar os fluxos em escala fina de tempo (menos que uma hora) além de fornecerem medições contínuas; nas suas desvantagens se incluem a sensibilidade às predisposições dos instrumentos que medem os gradientes e os componentes do balanço de energia; a possibilidade de descontinuidade de dados quando a razão de Bowen se aproxima de -1 , e os requerimentos, comuns aos métodos micrometeorológicos, de "fetch" adequado para segurança das hipóteses do método (Todd et al., 2000).

Em face do exposto objetivou-se, com o presente trabalho, quantificar a partição do saldo de radiação, medida durante todo o ciclo fenológico da cultura do feijão caupi, nos fluxos de calor latente, sensível e no solo.

\section{MATERIAL E MÉTODOS}

As medidas para a realização do balanço de energia foram efetuadas numa área de 4,0 ha, localizada na fazenda Chã de Jardim, pertencente ao Centro de Ciências Agrárias da Universidade Federal da Paraíba, situada na microrregião do brejo paraibano, no município de Areia, no Estado da Paraíba (6 $0^{\circ} 58^{\prime} 12^{\prime \prime} \mathrm{S}$ e $35^{\circ} 42^{\prime} 15^{\prime \prime} \mathrm{O}$ e $\left.620 \mathrm{~m}\right)$. O clima na região, pela classificação de Köppen, é do tipo As' (quente e úmido), com estação chuvosa no período outono-inverno, cujas maiores precipitações ocorrem nos meses de junho e julho (Brasil, 1972).

O solo da área é classificado como Latossolo Amarelo (EMBRAPA, 1999) e apresentou as seguintes características químicas, determinadas utilizando-se as metodologias recomendadas pela EMBRAPA (1997): $\mathrm{pH}$ em água 5,2, P e K extraídos pelo método de Mehlich, 0,75 e $30 \mathrm{mg} \mathrm{dm}^{-3}$, respectivamente, matéria orgânica, $48 \mathrm{~g} \mathrm{dm}^{-3} \mathrm{e}$ CTC 10,90 $\mathrm{cmol}_{\mathrm{c}} \mathrm{dm}^{-3}$. O plantio da cultura foi realizado manualmente e se estendeu de 13 a 16/3/2002, e a colheita dos dias 10 a 14/6/2002 . O espaçamento entre filas foi de 1,0 m e, entre plantas, de 0,50 $\mathrm{m}$, sendo colocadas duas sementes por cova. Realizaram-se duas capinas manuais durante todo o ciclo fenológico do feijão, não se detectando a presença de pragas nem ocorrência de doenças.

Uma adubação em fundação foi efetuada e constou de 100 $\mathrm{kg} \mathrm{ha}^{-1}$ de sulfato de amônia, $200 \mathrm{~kg} \mathrm{ha}^{-1}$ de cloreto de potássio e $178 \mathrm{~kg} \mathrm{ha}^{-1}$ de superfosfato triplo.

$\mathrm{Na}$ área experimental foram escolhidas 5 plantas para a realização de medições da altura da cobertura vegetal, e as medidas realizadas semanalmente, desde o estabelecimento até a colheita da cultura.

A descrição das fases fenológicas da cultura do feijão caupi foi realizada de acordo com Bastos et al. (2001), a fase vegetativa se estendeu dos 9 aos 50 dias após o plantio, a fase reprodutiva dos 51 aos 73 dias, a fase de maturidade fisiológica se estendeu dos 74 aos 88 dias e a fase de senescência englobou 88 aos 94 dias; além disso, também se mediu a percentagem de área de solo ocupada pela cultura e, para que fosse possível realizar esta determinação, construiu-se um dispositivo que consistia de um mastro e de uma base para o apoio de uma máquina fotográfica digital e de um retângulo de área conhecida, o qual era colocado em 4 áreas previamente selecionadas, com vistas ao acompanhamento da evolução da cobertura foliar. Após serem tiradas as fotografias com máquina digital, as mesmas eram transferidas para um computador, no qual, com o auxílio do programa "Image Tool” (versão 3.0), se procedia ao cálculo da área ocupada pelas plantas.

Para a realização do balanço de energia foi instalada uma torre no centro da área contendo dois sensores de medidas da temperatura e da umidade relativa do ar, em dois níveis $(\mathrm{z}=$ 35,0 e z $z_{2}=105,0 \mathrm{~cm}$ ) acima do dossel da cultura. Com a evolução da altura da cultura, ocorria elevação da altura desses sensores, de modo que os níveis de medição se mantivessem nas alturas estabelecidas; além desses sensores, ainda se instalou um piranômetro para a medida da radiação global, um saldo radiômetro para as medições do saldo de radiação e um pluviógrafo, para a medida da precipitação pluviométrica; esses sensores foram instalados na mesma torre, na altura de $1,5 \mathrm{~m}$ 
da superfície do solo; já para a medida do fluxo de calor no solo instalaram-se fluxímetros em dois locais, na profundidade $\mathrm{z}_{1}=$ $5,0 \mathrm{~cm}$, juntamente com um sensor de umidade do solo, na mesma profundidade, além de duas sondas térmicas instaladas horizontalmente, nas profundidades de $\mathrm{z}_{1}=2,0$ e $\mathrm{z}_{2}=8,0 \mathrm{~cm}$. Todas essas medidas foram armazenadas como médias a cada 30 min, com exceção da pluviometria, quando foi calculado seu valor total, em um sistema de aquisição de dados CR 10X da Campbell Scientific.

O fluxo de calor na superfície do solo $(\mathrm{G})$ foi dado de acordo com Kustas et al. (2000):

$$
\mathrm{G}=\mathrm{G}_{\mathrm{p}}+\frac{\Delta \mathrm{T}_{\mathrm{S}} \mathrm{CD}}{\mathrm{t}}
$$

sendo $G_{p}$ a medição do fluxo de calor pelo fluxímetro, $\Delta T_{S}$ a variação na temperatura média do solo $\left({ }^{\circ} \mathrm{C}\right)$ durante o período de medição, $\mathrm{C}$ a capacidade térmica volumétrica do solo $\left(\mathrm{MJ} \mathrm{m}{ }^{-3}{ }^{\circ} \mathrm{C}^{-1}\right)$, D é a profundidade do fluxímetro $(\mathrm{m})$ e t é a duração do período de medição (s).

$\mathrm{O}$ valor de $\mathrm{C}$ foi estimado somando-se as capacidades caloríficas dos vários constituintes do solo, ponderados de acordo com suas frações de volume, com base em de Vries (1966):

$$
\mathrm{C}=1,92 \mathrm{f}_{\mathrm{m}}+2,51 \mathrm{f}_{0}+4,18 \theta
$$

sendo: $\mathrm{f}_{\mathrm{m}}$ a fração de volume dos minerais, $\mathrm{f}_{0}$ a fração de volume da matéria orgânica e $\theta$ a umidade volumétrica do solo.

O balanço de energia na superfície do solo pode ser escrito por meio da seguinte equação (Perez et al., 1999; Todd et al., 2000):

$$
\mathrm{Rn}=\mathrm{G}+\mathrm{H}+\mathrm{LE}
$$

donde Rn é o saldo de radiação $\left(\mathrm{W} \mathrm{m}^{-2}\right), \mathrm{G}$ o fluxo de calor no solo $\left(\mathrm{W} \mathrm{m}^{-2}\right)$, H o fluxo de calor sensível $\left(\mathrm{W} \mathrm{m}^{-2}\right)$ e LE o fluxo de calor latente $\left(\mathrm{W} \mathrm{m}^{-2}\right)$.

A partição da energia disponível $(\mathrm{Rn}-\mathrm{G})$ entre fluxo de calor latente e fluxo de calor sensível, pode ser obtida pelo método do balanço de energia, baseado na razão de Bowen, obtida com as diferenças na temperatura do ar e na pressão de vapor, em dois níveis (Perez et al., 1999):

$$
\beta=\frac{\mathrm{H}}{\mathrm{LE}}=\gamma \frac{\Delta \mathrm{T}}{\Delta \mathrm{e}}
$$

em que $\gamma$ é a constante psicrométrica $\left(0,066 \mathrm{kPa}{ }^{\circ} \mathrm{C}^{-1}\right) ; \Delta \mathrm{T}$ a diferença de temperatura do $\operatorname{ar}\left({ }^{\circ} \mathrm{C}\right)$ e $\Delta$ e a diferença da pressão de vapor $(\mathrm{kPa})$.

A partir das medições do saldo de radiação $(\mathrm{Rn})$, do fluxo de calor no solo $(\mathrm{G})$ e das diferenças de temperatura do ar $(\Delta \mathrm{T})$ e da pressão de vapor $(\Delta \mathrm{e})$, juntamente com a equação simplificada do balanço de energia (Eq. 3) e se utilizando a razão de Bowen ( $\beta$ ) (Eq. 4), procedeu-se ao cálculo dos fluxos de calor latente (LE) e calor sensível $(\mathrm{H})$ segundo as equações:

$$
\begin{gathered}
\mathrm{LE}=\frac{\mathrm{Rn}-\mathrm{G}}{1+\beta} \\
\mathrm{H}=\frac{\beta}{1+\beta}(\mathrm{Rn}-\mathrm{G})
\end{gathered}
$$

\section{RESULTADOS E DISCUSSÃO}

Na Figura 1 são apresentados os dados da evolução da cobertura vegetal e da percentagem de cobertura do solo.

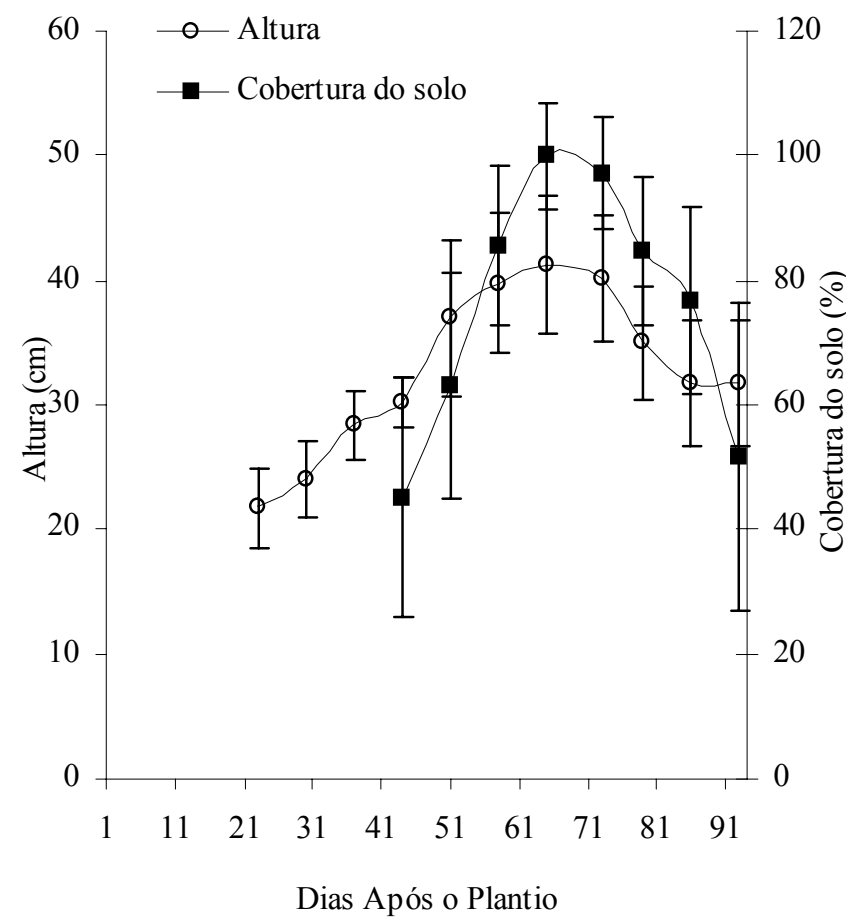

Cada ponto representa a média de cinco (altura da cobertura vegetal) e quatro repetições (cobertura do solo). As barras indicam o desvio padrão

Figura 1. Evolução da altura da cobertura vegetal e da percentagem de cobertura do solo durante o período de 13/ $3 / 2002$ a $14 / 6 / 2002$

Nota-se que, aos 23 dias após o plantio (DAP) a altura média da cobertura vegetal era de $21,8 \pm 3,2 \mathrm{~cm}$; aos 44 DAP era de 30,3 $\pm 2,06 \mathrm{~cm}$, com taxa de velocidade de crescimento médio de $0,4 \mathrm{~cm} \mathrm{~d}^{-1}$; aos 51 DAP, a altura média da cobertura vegetal é de $37,0 \pm 6,3 \mathrm{~cm}$, com taxa de velocidade de crescimento médio de $0,96 \mathrm{~cm} \mathrm{~d}^{-1}$, sendo que a maior altura da cobertura vegetal ocorreu aos 65 DAP, com valor médio de 41,3 $\pm 5,5 \mathrm{~cm}$ e taxa de velocidade de crescimento de $0,22 \mathrm{~cm} \mathrm{~d}^{-1}$ para, em seguida, começar a ocorrer declínio da altura da cobertura vegetal, a medida em que a cultura vai chegando às fases de maturidade fisiológica e senescência.

Observa-se, ainda, que a evolução da cobertura do solo acompanha a evolução da altura da cobertura vegetal, o que era esperado, uma vez que, com maior crescimento, ocorre também maior cobertura do solo. A máxima cobertura do solo se dá justamente quando a cobertura vegetal chega à sua maior altura, ou seja, aos 65 DAP. Do mesmo modo que a altura, a 
cobertura do solo começa a declinar sempre que a cultura vai chegando às fases de maturidade fisiológica e senescência.

A precipitação pluviométrica ocorrida durante o ciclo de cultivo do feijão caupi no ano de 2002, é apresentada na Figura 2.

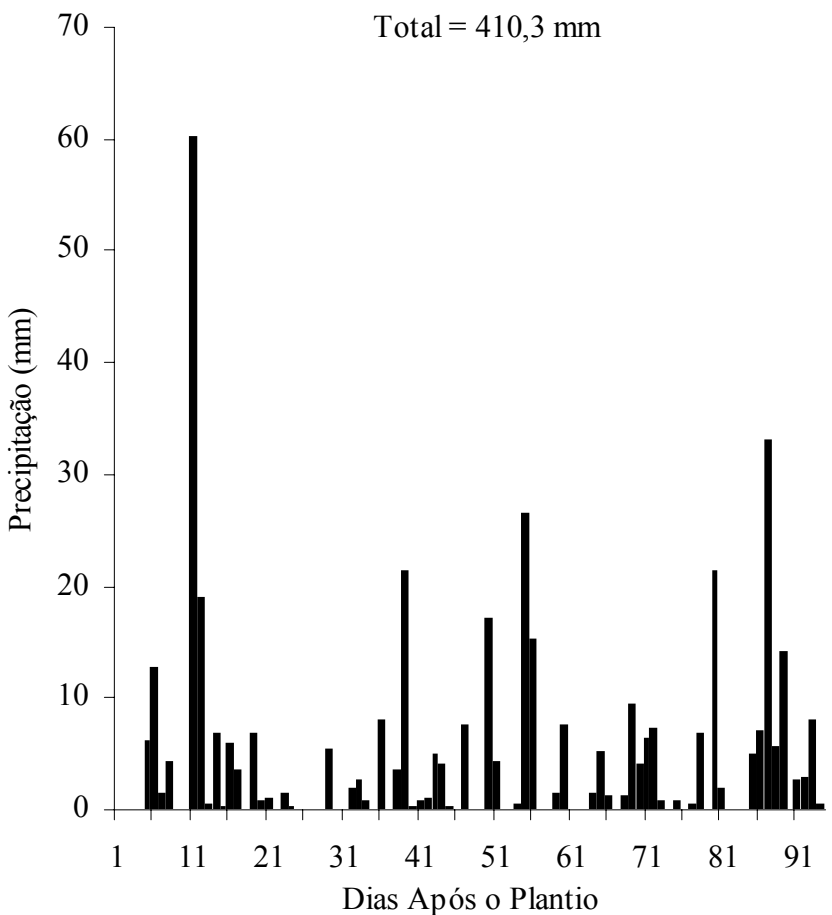

Figura 2. Precipitação pluviométrica durante o período de 13/3/2002 a 14/6/2002, em Areia, PB

Observa-se, no período de 13/3/2002 a 14/6/2002, um total de chuvas de $410,3 \mathrm{~mm}$, sendo sua distribuição regular durante todo o período, a não ser do dia $1 / 4$ ao dia $16 / 4$, isto é, dos 20 aos $35 \mathrm{DAP}$, com somente $14 \mathrm{~mm}$ de chuva. Verifica-se, ainda, que dos 94 dias de estudo 34 não sofreram precipitação pluviométrica, mas em 50 dias, ocorreram precipitações de até $10 \mathrm{~mm}$ e somente 10 dias tiveram precipitações maiores que 10 $\mathrm{mm}$, cujo maior evento de chuva $(60 \mathrm{~mm})$ se deu aos 11 DAP, ou seja, no dia 23/03/2002. Conclui-se, então, que as chuvas foram caracterizadas por pequena intensidade mas com freqüência elevada.

A variação diária da relação entre o saldo de radiação $(R n)$ e a radiação global $(\mathrm{Rg})$ é apresentada na Figura 3.

A fração de radiação solar global transformada em energia disponível ao sistema, ou seja, saldo de radiação, apresenta distribuição regular e valor médio de $0,78 \pm 0,03$, alcançando valor máximo de 0,85 aos 7 e 8 DAP, enquanto os menores valores observados se concentraram no período dos 25 aos 35 DAP, isto é, dos dias 6 a 15/4/2003, período em que a cultura se encontrava no estágio de desenvolvimento vegetativo; isto ocorreu porque o solo seco tinha, provavelmente, um albedo e uma temperatura de superfície maior que o solo úmido (Allen et al.,1994), uma vez que na época, como indica a Figura 2, só choveu $14 \mathrm{~mm}$ fazendo com que ocorresse uma elevação do albedo, com conseqüente diminuição do balanço de radiação de ondas curtas e uma elevação da temperatura da superfície, com conseqüente elevação da radiação de ondas longas emitida

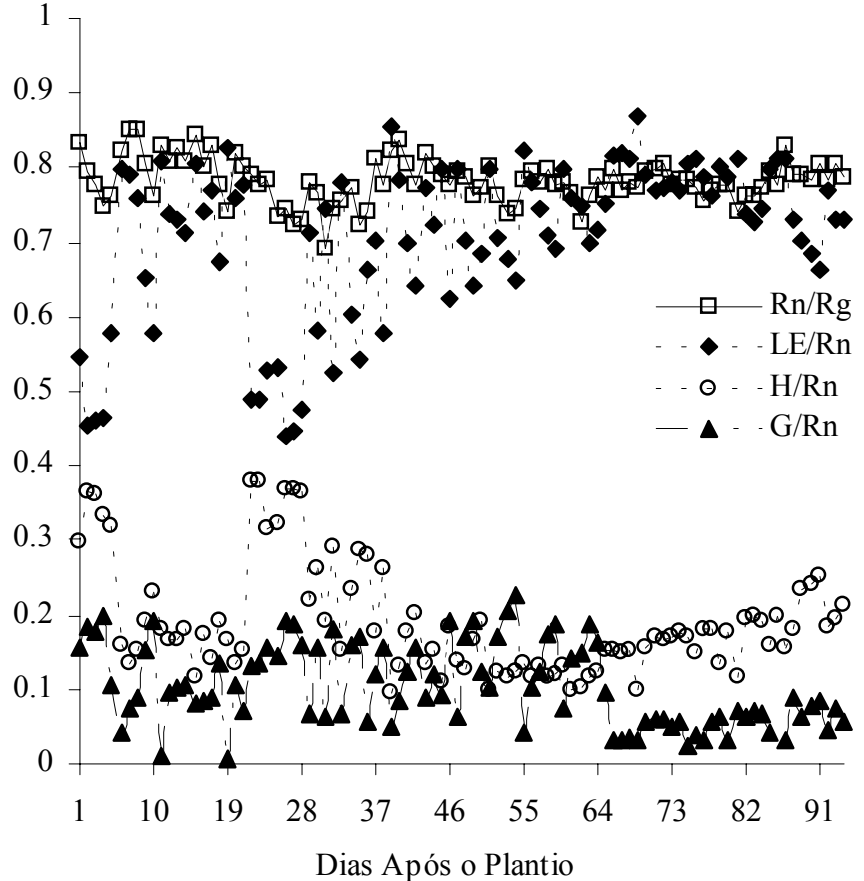

Figura 3. Variação diária da relação entre o saldo de radiação $(\mathrm{Rn})$ e a radiação solar global $(\mathrm{Rg})$, e entre o saldo de radiação e os fluxos de calor latente (LE), sensível (H) e no solo (G), na cultura do feijão Caupi, durante o período de 13/3/2002 a 14/6/2002, em Areia, PB

pela superfície do solo; ambos os fatores concorrem para um saldo menor de radiação (Rn). Este comportamento também foi observado nas condições semi-áridas da Nigéria para um solo sem vegetação (Wallace \& Holwill, 1997).

Na Figura 3 são apresentados, também, os valores da partição do saldo de radiação entre os fluxos de calor latente (LE), sensível (H) e no solo (G).

Vê-se que a maior porção do saldo de radiação $(\mathrm{Rn})$ foi utilizada como fluxo de calor latente (LE), com valor médio de $0,71 \pm 0,11$ para todo o período estudado. Os menores valores $(0,45-0,55)$ foram encontrados nos primeiros dias de cultivo, sendo que, nesta fase, o solo se encontrava sem cobertura vegetal (Figura 1), e dos 22 aos 28 DAP $(0,44-0,53)$, ocasião em que o conteúdo de água no solo era menor, devido a uma quantidade menor de chuvas ocorridas no período (Figura 2).

$\mathrm{O}$ valor médio da porção do saldo de radiação utilizada como fluxo de calor sensível foi $0,19 \pm 0,07$, com os maiores valores $(0,30-0,36)$ no início do cultivo, e dos 22-28 DAP $(0,32-$ $0,38)$ devido, como já referido, à menor quantidade de chuvas nesse período mas, a partir dos 40 até aos $88 \mathrm{DAP}$, ocorre estabilização desses valores, em torno de 0,15 para, em seguida, haver aumento no final do cultivo $(0,22)$. Tal estabilização se deu, provavelmente, em virtude de uma cobertura maior do solo pela cultura (Figura 1) e pela excelente distribuição de chuvas na época, em torno dos $230 \mathrm{~mm}$, ou seja, $56 \%$ do total; já o aumento dessa relação (H/Rn) no final do cultivo, se deve à cultura em fase de senescência, não se utilizando mais água para os seus processos fisiológicos, além do fato do solo se encontrar mais descoberto.

Por outro lado, a porção do saldo de radiação (Rn) utilizada para o fluxo de calor no solo $(\mathrm{G})$, teve valor médio de $0,10 \pm$ 
0,05 , cujos maiores valores encontrados foi no início do cultivo, visto que o solo se encontrava sem cobertura vegetal, e dos 26-28 DAP, ocasião em que o solo apresentava baixo conteúdo de água; nota-se, ainda, dos 66 DAP até o fim do cultivo, uma drástica redução da razão $\mathrm{G} / \mathrm{Rn}$, devido à maior cobertura do solo pela cultura (Figura 1).

San José et al. (2003) trabalhando com duas cultivares de feijão caupi na Venezuela encontraram que, durante todo o ciclo da cultura, cerca de $72 \%$ da energia disponível (Rn - G) foram utilizados como fluxo de calor latente.

A variação diária dos componentes do balanço de energia e da radiação global sobre a cultura do feijão caupi, é apresentada na Figura 4, na qual os totais diários de $\mathrm{Rg}, \mathrm{Rn}$, $\mathrm{LE}, \mathrm{H} \mathrm{e} \mathrm{G}$, foram integrados utilizando-se os valores do nascer ao pôr-do-sol, ou seja, das 6:00 às 18:00 h.

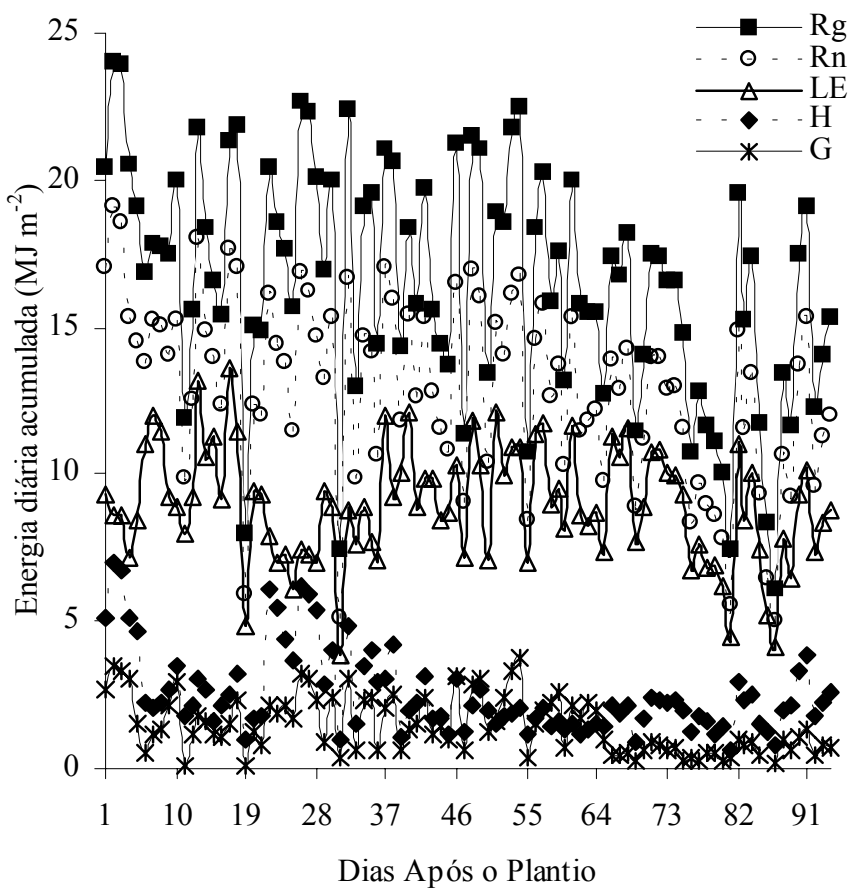

Figura 4. Variação diária da radiação global $(\mathrm{Rg})$, do saldo de radiação $(\mathrm{Rn})$, do fluxo de calor latente (LE), do fluxo de calor sensível $(\mathrm{H})$ e do fluxo de calor no solo $(\mathrm{G})$, na cultura do feijão Caupi, durante o período de 13/3/2002 a 14/6/2002, em Areia, PB

Observa-se que as variações do fluxo de calor latente (LE) seguem as variações do saldo de radiação $(R n)$ e estas, por sua vez, seguem as variações da radiação global $(\mathrm{Rg})$. De acordo com Teixeira (2001), esta simetria sugere que, através da obtenção ou estimativa dos valores do saldo de radiação sobre a cultura, durante as diferentes fases fenológicas, o produtor já possui critérios para determinar o consumo de água pela cultura, para o manejo da irrigação.

Os valores de Rg diários variaram entre 24,00 e 6,09 $\mathrm{MJ} \mathrm{m}^{-2}$ com valor médio de $16,53 \pm 4,01 \mathrm{MJ} \mathrm{m}^{-2}$, os valores da $\mathrm{Rn}$ oscilaram entre 19,10 e 5,06 $\mathrm{MJ} \mathrm{m}^{-2}$ com valor médio de $12,94 \pm$ $3,14 \mathrm{MJ} \mathrm{m}^{-2}$, enquanto os valores de LE oscilaram entre 13,6 e $3,82 \mathrm{MJ} \mathrm{m}^{-2}$, com valor médio de $8,95 \pm 1,99 \mathrm{MJ} \mathrm{m}^{-2}$. San José et al. (2003), para as condições das savanas neotropicais da Venezuela encontraram, para uma cultivar de feijão caupi
(TC-9-6), valores médios do saldo de radiação iguais a 12,00 $\mathrm{MJ} \mathrm{m}^{-2}$ e de fluxo de calor latente iguais a $8,45 \mathrm{MJ} \mathrm{m}^{-2}$, ou seja, valores muito próximos dos encontrados neste trabalho.

Observa-se, ainda, que os valores de $\mathrm{H}$ variaram entre 6,96 e $0,64 \mathrm{MJ} \mathrm{m}^{-2}$ com valor médio de $2,54 \pm 1,41 \mathrm{MJ} \mathrm{m}^{-2}$. O fluxo de calor sensível $(\mathrm{H})$ apresentou seus maiores valores (4,63-6,96 $\mathrm{MJ} \mathrm{m}^{-2}$ ) no início do cultivo, ou seja, de 1-5 DAP, e aos 25-31 DAP (4,36-6,11 $\mathrm{MJ} \mathrm{m}^{-2}$ ) para, em seguida, começar a declinar. Este comportamento do fluxo de calor sensível pode ser explicado pelo fato de que, após os 37-40 DAP, a cultura do feijão começa a sua fase de maior crescimento, fazendo com que aumente a cobertura do solo pela cultura (Figura 1) e, deste modo, a maior parte do saldo de radiação seja utilizada para a transpiração das plantas.

O mesmo comportamento apresenta o fluxo de calor no solo (G), em que seus valores mais elevados se encontram na fase inicial de desenvolvimento da cultura, para diminuir com o aumento da cobertura do solo, embora seus valores oscilem entre 3,80 e 0,05 $\mathrm{MJ} \mathrm{m}^{-2}$, com valor médio de $1,46 \pm 0,96 \mathrm{MJ} \mathrm{m}^{-2}$.

San José et al. (2003) encontraram valores médios de 3,24 e $0,31 \mathrm{MJ} \mathrm{m}^{-2}$ para os fluxos de calor sensível e de calor no solo, respectivamente.

A variação horária dos componentes do balanço de energia na cultura do feijão caupi durante a fase de emergência, é apresentada na Figura 5, na qual se nota que o dia 13/3/2002 (1 DAP) se apresentou como um dia em que os fluxos de calor latente (LE) e de calor sensível $(\mathrm{H})$ foram aproximadamente iguais, enquanto no dia 19/3/2002 (7 DAP) o fluxo de calor latente foi bem maior que o fluxo de calor sensível. O saldo de radiação $(\mathrm{Rn})$ foi bem parecido durante os dois dias, enquanto o fluxo de calor no solo (G) foi bem maior no dia 13/3/2002 que no dia 19/3/2002. Este comportamento dos fluxos de calor latente, sensível e no solo para o dia 13/3/2002, indica que o solo se encontrava com restrição hídrica, já que só tinha chovido $6,5 \mathrm{~mm}$ no dia $12 / 3 / 2002$, mas para o dia 19/3/2002 ocorrera precipitação acumulada em torno de $20 \mathrm{~mm}$, fazendo com que houvesse elevação do fluxo de calor latente, com conseqüente diminuição dos valores dos fluxos de calor sensível e no solo.

O comportamento observado nos dias 13/3/2002 e 19/3/2002 mostra os processos que ocorrem na superfície do solo

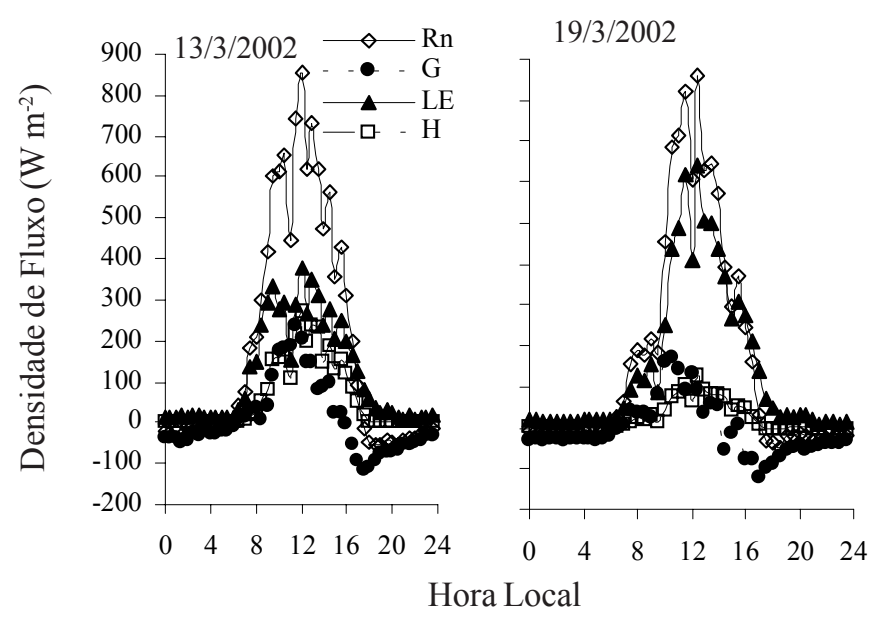

Figura 5. Variação horária dos componentes do balanço de energia na cultura do feijão caupi, durante a fase de emergência 
descoberto já que, quanto maior o conteúdo de água no solo, maior também a quantidade de energia utilizada no processo de evaporação da água do solo; contudo, quando se inicia a secagem do solo, a maior parte do saldo de radiação começa a ser usada no processo de aquecimento do ar e do solo, já que nesta fase de emergência a cultura não exerce nenhum papel nos processos de troca de energia, na interface solo-plantaatmosfera.

A variação horária dos componentes do balanço de energia, quando a cultura se encontrava na fase vegetativa, é apresentada na Figura 6.

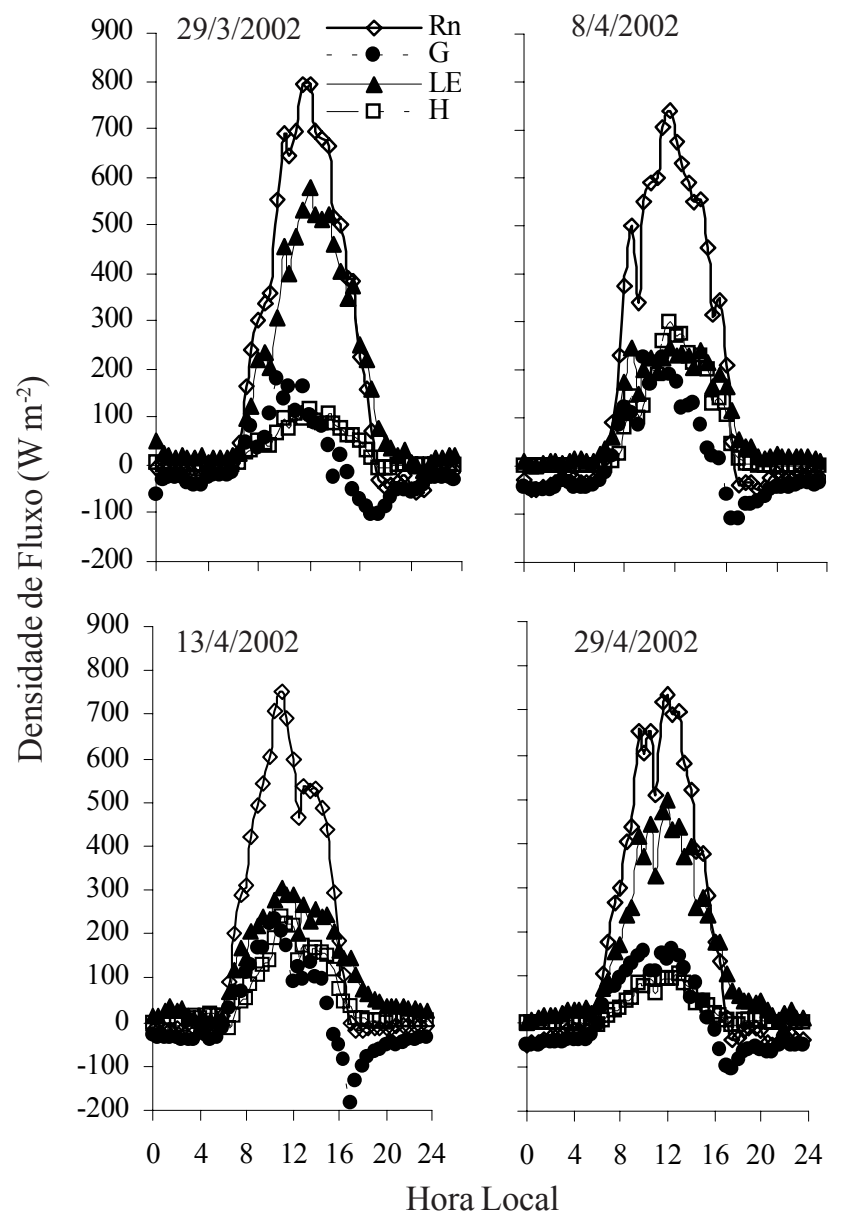

Figura 6. Variação horária dos componentes do balanço de energia na cultura do feijão caupi, durante a fase vegetativa

No dia 29/3/2002 (17 DAP), o fluxo de calor latente (LE) foi bem maior que os fluxos de calor sensível $(H)$ e no solo $(G)$, embora esses dois fluxos tenham apresentado valores muito próximos; já no dia 08/4/2002 (27 DAP), constatou-se aumento nos valores de $\mathrm{G}$ e $\mathrm{H}$, além de redução no valor de $\mathrm{LE}$, fazendo com que $\mathrm{H}$ ficasse muito próximo de LE. O mesmo comportamento foi observado para o dia 13/4/2002 (32 DAP), em que os valores dos fluxos de calor latente e de calor sensível ficaram próximos e os valores dos fluxos de calor no solo permaneceram elevados, enquanto o dia 29/4/2002 (48 DAP) apresentou comportamento idêntico ao do dia 29/3/2002 (17 DAP), visto que os valores dos fluxos de calor latente foram bem superiores aos valores dos fluxos de calor sensível e no solo e esses dois últimos apresentaram valores semelhantes.
Esta variação dos fluxos de calor latente, de calor sensível e de calor no solo pode, novamente, ser explicada pela quantidade de água disponível no sistema solo-plantaatmosfera, já que os dias que apresentaram os maiores valores do fluxo de calor latente, corresponderam aos períodos em que ocorreram as maiores precipitações para esta fase fenológica, com 96,2 mm para o período de 23/3/2002 a 29/3/2002 e com 40,1 mm para o período de 20 a 29/4/2002, enquanto nos dias em que os fluxos de calor sensível e no solo (8/4/2002 e 15/4/2002) tiveram seus valores mais elevados, o total de chuvas neste período foi de somente $10,6 \mathrm{~mm}$. Outro fator que pode influir na partição do saldo de radiação nos fluxos de calor latente, sensível e no solo, é a cobertura do solo pela cultura, mas parece que este fator ainda não estava influenciando na partição do saldo de radiação, tendo em vista que os dias 29/3/2002 e 29/4/2002 se mostraram muito semelhantes e no dia 29/4/2002 a cobertura do solo pela cultura era de $43 \%$ (Figura 2); portanto, a cobertura do solo pela cultura no dia 29/3/2002 era bem menor, sendo esperado um comportamento diferenciado entre esses dois dias, principalmente para o fluxo de calor no solo, de vez que, com o aumento da cobertura do solo, espera-se diminuição neste fluxo; assim, os fatores atmosféricos estão participando bem mais efetivamente que os fatores da cultura, na variação dos componentes do balanço de energia durante a fase vegetativa do feijão caupi.

A variação horária dos componentes do balanço de energia durante a fase reprodutiva, é apresentada na Figura 7, na qual se observa, para todos os dias, que o fluxo de calor latente (LE) é o principal componente do balanço de energia, independentemente das condições de umidade do solo. Os valores do fluxo de calor sensível $(\mathrm{H})$ apresentaram-se quase que constantes para todos os dias estudados, enquanto o fluxo de calor no solo $(\mathrm{G})$ apresentou seu valor mais elevado no dia 4/5/2002 (53 DAP) para, em seguida, mostrar redução bem acentuada dos seus valores, nos dias subseqüentes. Este comportamento dos componentes do balanço de energia para a fase reprodutiva, já reflete a influência do fator planta, pois no dia 4/5/2002, apesar de só ter chovido $4 \mathrm{~mm}$ no dia $2 / 5 / 2002$, o fluxo de calor latente ainda apresentava valores bem elevados, de onde se supõe que está ocorrendo extração de água do solo pelo sistema radicular da cultura, em camadas mais profundas contribuindo, desta forma, para a manutenção dos elevados valores do fluxo de calor latente. No dia 7/5/2002 (56 DAP), que apresentava percentagem de cobertura do solo pela cultura de 84\% (Figura 1), os maiores valores de fluxo de calor latente devem ter ocorrido em função da quantidade de chuvas verificadas nos dias 6 e 7/5/2002, que totalizaram $41,7 \mathrm{~mm}$, e da maior cobertura do solo pela cultura, contribuindo também para os menores valores de fluxo de calor sensível e no solo.

Para o dia 18/5/2002 (67 DAP) os valores do fluxo de calor latente permaneceram elevados, porém só havia chovido 6,4 mm entre os dias 16 e 17/05, período em que a cultura cobria totalmente a superfície do solo confirmando, assim, a influência da planta na partição do saldo de radiação, enquanto o dia 22/ 05 (71 DAP), além de apresentar elevada percentagem de cobertura do solo pela cultura, em torno dos 95\% (Figura 1), chovera em torno de $20 \mathrm{~mm}$ entre os dias 20 e 22/05 contribuindo, 


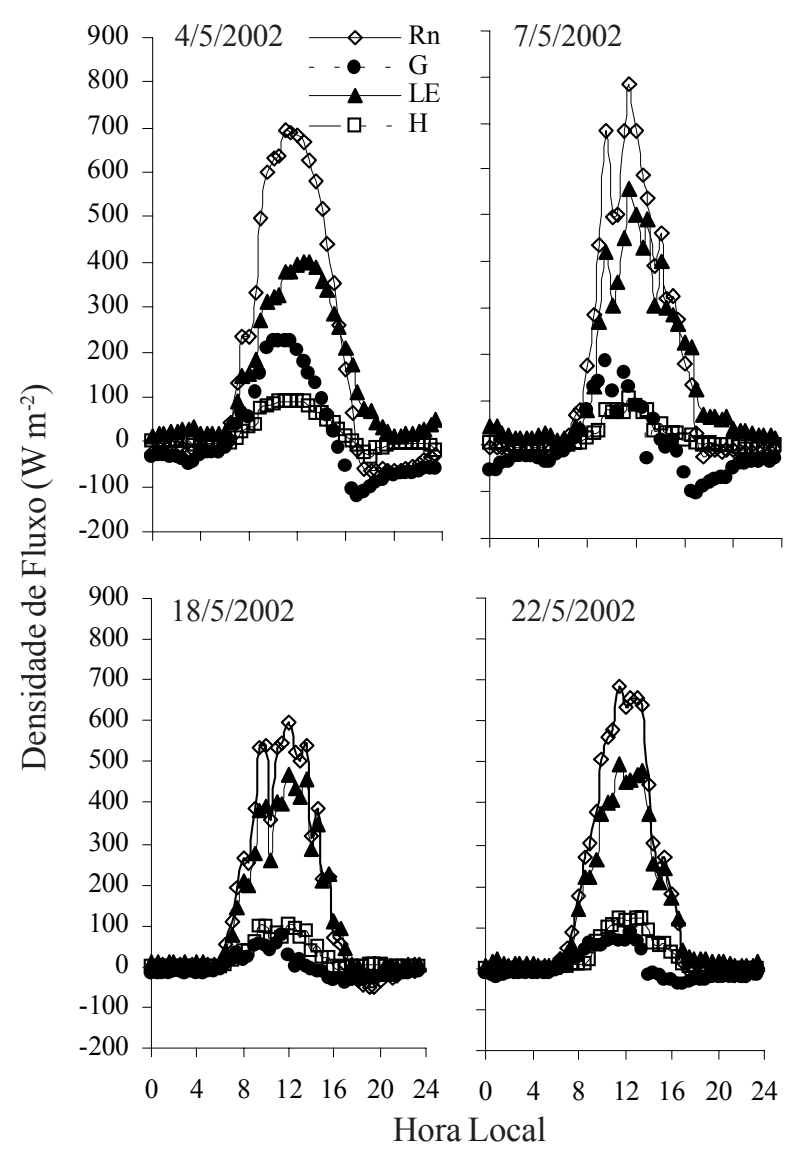

Figura 7. Variação horária dos componentes do balanço de energia na cultura do feijão caupi, durante a fase reprodutiva

daí, para os maiores valores do fluxo de calor latente e para os menores valores dos fluxos de calor sensível e no solo.

Durante a fase reprodutiva a cultura utiliza quantidade de água bem maior nos seus processos fisiológicos que nas fases anteriores; o valor médio da razão $\mathrm{LE} /(\mathrm{Rn}-\mathrm{G})$ nessa fase foi de 0,85 enquanto na fase vegetativa foi de 0,76 ; deste modo, ocorre aumento da evapotranspiração, o que fica bem ilustrado neste trabalho, pois nos dias 4/5/2002 e 7/5/2002, a razão LE/(Rn-G) foi igual a 0,85 e 0,87 , respectivamente. Por esses dados concluise que, nesta fase fenológica, mais de $85 \%$ da energia disponível foram utilizados no processo de evapotranspiração. San José et al. (2003) encontraram, durante a fase reprodutiva do feijão caupi, valores médios da razão LE/(Rn - G) de 0,79, ou seja, $79 \%$ da energia disponível foram utilizados para o processo de evapotranspiração da cultura.

A variação horária dos componentes do balanço de energia durante as fases de maturidade fisiológica e de senescência, é apresentada na Figura 8.

Vê-se que, durante a fase de maturidade fisiológica, dia 2/6/ 2002 (82 DAP), o fluxo de calor latente continua a ser o principal componente do balanço de energia, fato que ocorre tanto por causa da maior cobertura do solo pela vegetação, quanto pela quantidade de água precipitada nos dias 31/5/2002 e 1/6/2002, que totalizou $23 \mathrm{~mm}$. Os maiores valores do fluxo de calor sensível quando comparados aos do fluxo de calor no solo, devem ser devidos à maior cobertura do solo, já que, com esta maior cobertura, deve chegar menos radiação solar global diretamente na superfície do solo.

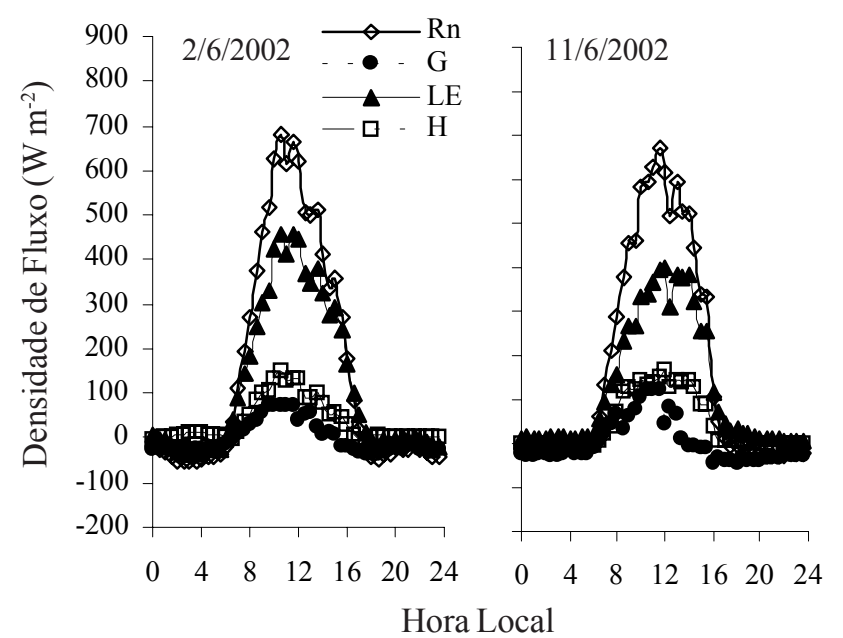

Figura 8. Variação horária dos componentes do balanço de energia na cultura do feijão caupi, durante as fases de maturidade fisiológica $(2 / 6 / 2002)$ e de senescência $(11 / 6$ / 2002)

Na fase de senescência, dia 11/6/2002 (91 DAP), acontece elevação dos fluxos de calor sensível e de calor no solo devido, provavelmente, a uma exposição maior do solo à radiação global, já que nesta fase a cultura perde a maior parte de suas folhas, fazendo com que ocorra diminuição da área de solo coberta pela cultura, em torno dos $60 \%$ (Figura 1 ).

Ressalta-se que, apesar de haver chovido $67 \mathrm{~mm}$ do dia 2/6/ 2002 até o dia 11/6/2002, os valores dos fluxos de calor latente no dia 2/6/2002 são maiores que os do dia $11 / 6 / 2002$, fato explicado pelo fato de que no dia 2/6/2002 a cultura ainda utilizava água para os seus processos fisiológicos, enquanto no dia 11/6/2002 ela já se encontrava em senescência, e esses valores de fluxo de calor latente devem ser principalmente da evaporação da água do solo.

\section{CONCLUSÕES}

1. A radiação solar global $(\mathrm{Rg})$ transformada em saldo de radiação $(\mathrm{Rn})$ teve, como valor médio $78 \%$, durante todo o ciclo da cultura, apresentando distribuição regular.

2. O saldo de radiação sobre a cultura do feijão caupi nas condições do Brejo Paraibano é utilizado, em média, como 71\% no fluxo de calor latente, $19 \%$ como fluxo de calor sensível e $10 \%$ como fluxo de calor no solo.

3. Com exceção dos períodos mais secos, as variações do fluxo de calor latente (LE) seguiram as variações do saldo de radiação $(\mathrm{Rn})$.

4. A fração do saldo de radiação utilizada como fluxo de calor latente aumentou com a evolução da cobertura do solo pela cultura, enquanto a fração utilizada como fluxo de calor sensível e de calor no solo, diminuiu.

\section{LITERATURA CITADA}

Albuquerque, P.E.P. Evapotranspiração, balanços de energia e de água no solo e índices de estresse hídrico da cultura, em feijoeiro (Phaseolus vulgaris L.) submetido a diferentes freqüências de irrigação em Sete Lagoas, MG. Botucatu: UNESP, 1997, 70p. Tese Doutorado 
Allen, S.J.; Wallace, J.S.; Gash, J.H.C.; Sivakumar, M.V.K. Measurements of albedo variation over natural vegetation in the Sahel. International Journal of Climatology, Berkshire, v.14, n.6, p.625-636, 1994.

Bastos, E.A.; Folegatti, M.V.; Faria, R.T.; Andrade Júnior, A.S.; Cardoso, M.J. Simulation of growth and development of irrigated cowpea in Piauí State by CROPGRO model. Pesquisa Agropecuária Brasileira, Brasília, v.37, n.10, p.13811387, 2001.

Brasil. Ministério da Agricultura. Equipe de Pedologia e Fertilidade do Solo. Divisão de Agrologia - SUDENE. Levantamento exploratório - reconhecimento de solos do Estado da Paraíba. Rio de Janeiro: 670p. 1972. Boletim Técnico 15

Cordeiro, L.G.; Bezerra, F.M.L.; Santos, J.J.A.; Miranda, E.P. Fator de sensibilidade ao déficit hídrico da cultura do feijão Caupi (Vigna unguiculata (L). Walp.). Revista Brasileira de Engenharia Agrícola e Ambiental, Campina Grande, v.2, n.2, p.153-157, 1998.

de Vries, D.A. Thermal properties of soils. In: van Wijk, W.R. (ed.). Physics of plant environment. Amsterdam: NorthHolland, 1966. p.210-233.

Ehlers, J.D.; Hall, A.E. Cowpea (Vigna unguiculata (L.) Walp). Field Crops Research, Amsterdam, v.53, n.1-3, p.187-204, 1997.

EMBRAPA - Empresa Brasileira de Pesquisa Agropecuária. Centro Nacional de Pesquisa de Solos. Manual de métodos de análise do solo. 2. ed. Rio de Janeiro: Embrapa Solos, 1997, 212p.

EMBRAPA - Empresa Brasileira de Pesquisa Agropecuária. Centro Nacional de Pesquisa de Solos. Sistema brasileiro de classificação de solos. 1.ed. Rio de Janeiro: Embrapa Solos, 1999, 412p.

Fontana, D.C.; Berlato, M.A.; Bergamaschi, H. Balanço de energia em soja irrigada e não irrigada. Pesquisa Agropecuária Brasileira, Brasília, v.26, n.3, p.403-410, 1991.

Fritschen, L.J.; Simpson, J.R. Surface energy balance and radiation systems: general description and improvements. Journal of Applied Meteorology, Boston, v.28, n.7, p.680689, 1989.
Kustas, W.P.; Prueger, J.H.; Hatfield, J.L.; Ramalingam, K.; Hipps, L.E. Variability in soil heat flux from a mesquite dune site. Agricultural and Forest Meteorology, Amsterdam, v.103, n.3, p.249-264, 2000.

Perez, P.J.; Castellvi, F.; Ibáñez, M.; Rosell, J.I. Assessment of reliability of Bowen ratio method for partitioning fluxes. Agricultural and Forest Meteorology, Amsterdam, v.97, n.3, p.141-150, 1999.

San José, J.J.; Bracho, R.; Montes, R.; Nikonova, N. Comparative energy exchange from cowpeas (Vigna unguiculata (L) Walp) cvs. TC-9-6 and M-28-6-6) with differences in canopy architectures and growth durations at the Orinoco llanos. Agricultural and Forest Meteorology, Amsterdam, v.116, n.3-4, p.197-219, 2003.

Sauer, T.J.; Hatfield, J.L.; Prueger, J.H.; Norman, J.M. Surface energy balance of a corn residue-covered field. Agricultural and Forest Meteorology, Amsterdam, v.89, n.3-4, p.155-168, 1998.

Silva, F.C. Determinação da evapotranspiração utilizando o método do balanço de energia e lisímetro de pesagem. Piracicaba: ESALQ, 2000, 72p. Tese Doutorado

Steduto, P.; Hsiao, T.C. Maize canopies under two soil water regimes IV. Validity of Bowen ratio-energy balance technique for measuring water vapor and carbon dioxide fluxes at 5 min intervals. Agricultural and Forest Meteorology, Amsterdam, v.89, n.3-4, p.215-228, 1998.

Teixeira, A.H.C. Avaliação dos componentes do balanço de energia durante o primeiro ano de cultura da banana. Revista Brasileira de Engenharia Agrícola e Ambiental, Campina Grande, v.5, n.1, p.28-32, 2001.

Todd, R.W.; Evett, S.R.; Howell, T.A. The Bowen ratio-energy balance method for estimating latent heat flux of irrigated alfalfa evaluated in a semi-arid, advective environment. Agricultural and Forest Meteorology, Amsterdam, v.103, n.4, p.335-348, 2000.

Wallace, J.S.; Holwill, C.J. Soil evaporation from tiger bush in Southwest Niger. Journal of Hydrology, Amsterdam, v.188189, n.1, p.426-442, 199 